\title{
INNOVATIONS
}

\section{A debt unpaid: The bibliographic instruction librarian and library conservation}

\author{
By Anthony J. Amodeo \\ Reference Librarian \\ Loyola Marymount University, Los Angeles
}

Another semester has ended. The mad rush to return books after term papers and finals is winding down, and the stacks are once again packed from side to side. They're all back, all those portable, user-friendly, no-batteries-needed conveyors of information, inspiration and, sometimes, wisdom. At least most of them are.

As always, a number of books have not returned: some will turn up in the (ugh!) bookdrop one summer's eve, with labels and perhaps pockets torn out, or imbrued with mud or mold or both. Others have permanently wended their merry way with gleeful graduates, dour dropouts, and, yes, even some supercilious part-time/temporary faculty members.

But also, as always, the dying wounded have come back. Battered by abuse, absurdly colorful in their new-found highlighted stripes and inkings-in, pitifully in pieces from gorilla mashings at the photocopier, knifed by careless re-shelvers, warped into coverlessness by sloppy shelving, maliciously mutilated by marauding Vandal-maleficents. . .

The list goes on. Sometimes, the response is "So what. They're out there to be used." Of course they are. USED. But in these days of throwaway mentality, library books are too often abused, treated like the returnable bottles that litter the highways. Watch the anxious businessman tear through a telephone book. Watch an undergraduate-or graduate student, faculty member, or librarian for that matter - tear through a reference book or periodical index or aged volume. Do you see any difference?

With some books, it may not matter. But with the growing number of "classics" in various disciplines now out of print-many of them with no real replacement possible - every thoughtless act of booktrashing adds up to a real loss in information; and that, ladies and gentlemen, is what this article is really about.

Librarians have long been around to a) collect, b) organize, c) preserve and d) make accessible the tenable pieces of human culture and information. Some functions have been stressed or neglected at different times, but these four functions are the fundamental reasons for our professional existence. Lately, preservation has again managed to struggle back into the more conscientious librarians' conscious concerns, especially as we see valuable information disappearing day after day, having done and being able do so iittle to stop its demise.

There are several ways at present which we use or are developing to preserve our disappearing information: microfilming, individual treatment of artifactual materials, technical innovations to capture information in digital form-none of which are, unfortunately, permanent solutions. But even if there was a way developed in the next few years to stop all paper deterioration with a magic wand-or a magic gas-the fact is that there will be a lot of important information lost forever in the meanwhile, information now readily available to students and others that will not exist in the library for the coming generation. When your library's copy of that classic treatise by Douglas Bush or Raymond Brown or Ortega y Gasset or Max Planck is made useless by a thief or vandal or merely a thoughtless reader, that treatise is effectively gone from your library forever. Out of print, out of library, out of mind.

Who tells today's students that books, even paperback books, are of value? Who trains them (as some of us were trained) to open new books carefully, how to turn pages, how to photocopy with- 


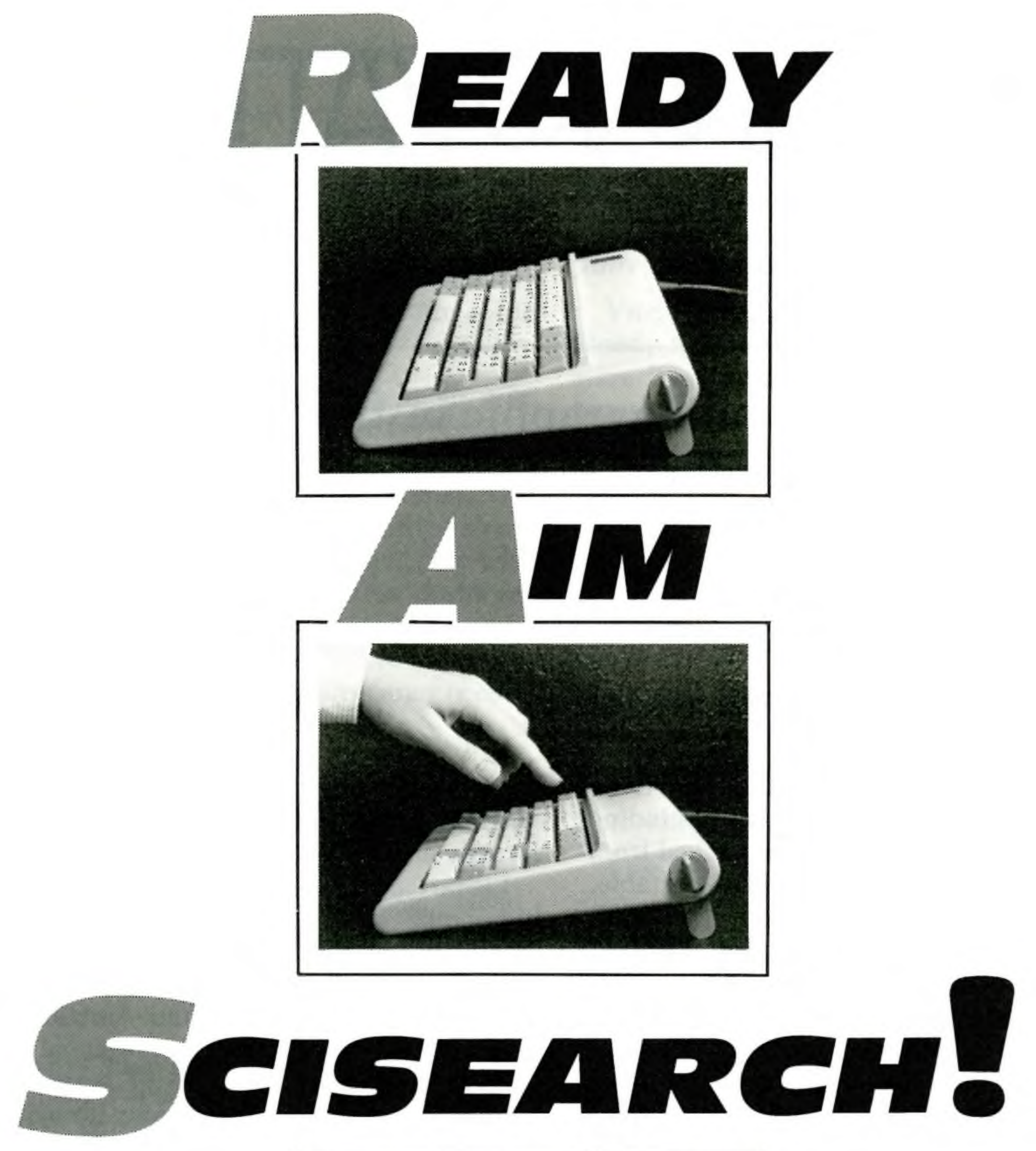

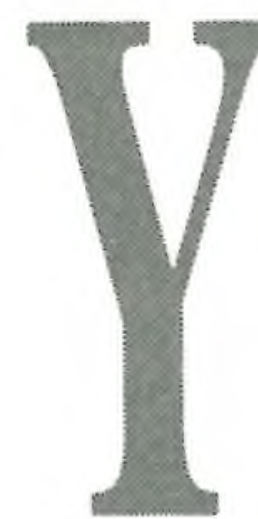

ou're just about to make a direct hit...online with SciSearch".

\section{Considering} you've accessed ISI's renowned Science Citation Index /Current Contents ${ }^{\text {(i) }}$ database, good hits are no surprise.

Because it's comprehensive. SciSearch indexes every significant item from the world's leading sci-tech journals.

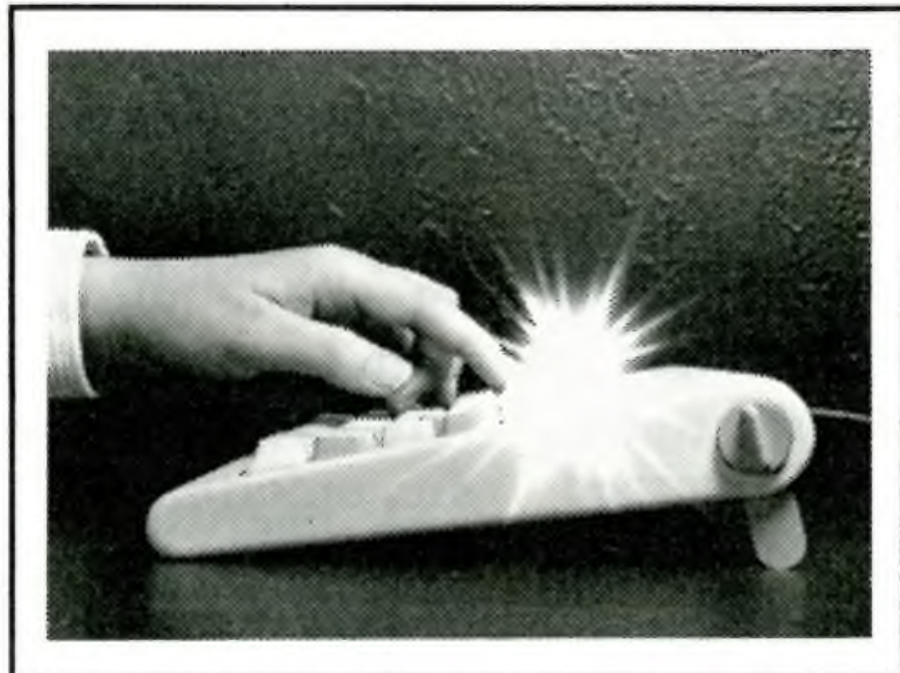

So if you'd like further instruction on how to take aim at one of the world's richest scientific databases, call or write us today-

In U.S.: 1-800-523-1857

In Canada: 1-800-523-1850, ext. 1591

Elsewhere:

123 High Street

Uxbridge, Middlesex UB8 1DP

United Kingdom

Phone: + 44-895-70016

to do with any of the sciences, SciSearch has it covered.

And it's highly accurate. Strict quality control is the key.

We don't think a literature search should be a hit-or-miss operation, and expect you don't either.

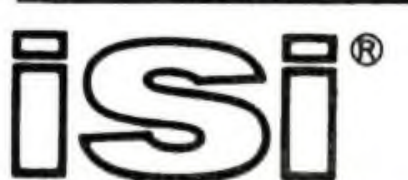

Institute for Scientific Information 3501 Market Street Philadelphia PA 19104 
out damage; not to crack the spines, not to use library books for doorstops, coasters, umbrellas, or read them in the hot tub? For the most part, no one. Elementary and high school teachers don't do it any more. Librarians at the reference desk often are so harried they imitate the students' bad bookhabits. There are of course posters, bookmarks, handouts, etc., that can serve to educate usersbut how many administrators will go along with spending money for user education in preservation? Even if they see that it saves the library money in the long run, their decision-making often has to be aimed at the very short run, just to meet the exhausted budget.

So, troops, it's really up to those librarians who have the most contact with students, whether oneon-one or in a classroom situation; and that, folks, is us.

"But how can we talk about library preservation when we've only got 50 minutes to give a 90 minute lecture? It's unrealistic."

I know the feeling. But it doesn't have to take up a lot of time. A couple of slides or transparencies, a little commonsense talk, and the couching of this material in terms of informational benefit to the students themselves will give you the ability to make an impact in less than a minute. And if you're really pressed for time, handing out bookmarks with some basic information about the fragility of books and the importance of good handling practices will still have some impact. And if you still say you don't have time: how about prefacing your lecture with some remarks on disappearing information, while you wait for the stragglers to show up? $\mathrm{BI}$ people are creative and inventive by nature or necessity. You'll think up a way!

Ponder this: the next time a student presents a real need for guidance to you at the Reference Desk, and you think of a book you yourself used that helped you begin your way through the problem (say, Prefaces to Shakespeare) - well, will it still be there for your student to use? It really is worth the extra effort.

\section{Self-instructed use of microcomputers in the library}

\author{
By James R. Coleman
}

\author{
Assistant Director
}

Suffolk University

\author{
and Edmund G. Hamann
}

Director, Mildred F. Sawyer Library
Suffolk University
Librarians are embracing the microcomputer as eagerly as they did the photocopy machine three decades ago. From the initial "Apple in the corner," academic libraries have quickly expanded to microcomputer centers with extensive arrays of IBM or Apple compatible computers. The affinity of microcomputers with libraries is apparent: central location, long hours, access and control for software, and the service orientation of the staff. ${ }^{1}$ The first three attributes of libraries, location, hours and control, are generally taken for granted. Service orientation, however, is more often a presumption than a fact, given the librarians' relative inexperience with the new technology and the significant investment in staff time required. Recent articles in library literature stress the need for librarians to train and organize themselves to teach their clientele how to retrieve and manipulate information on microcomputers, just as they are expected to give instruction in retrieving and using print materials. The example of the popularity of

${ }^{1}$ Linda J. Piele, Judith Pryor, and Harold W. Tuckett, "Teaching Microcomputer Literacy: New Roles for Academic Libraries," College \& Research Libraries 47i(July 1986): 374. the microcomputer instructional program at Cornell's Mann Library supports this view. ${ }^{2}$

Although microcomputing facilities are available at Suffolk University to serve several divisions of the institution, restrictions on their use encouraged the Mildred F. Sawyer Library to establish a small microcomputer center of its own. The library offers free, unscheduled access to microcomputers (as well as dedicated wordprocessors) set up with software to perform a variety of tasks from wordprocessing to retrieving and manipulating commercial data files. However, it does not have sufficient staff to mount a supervised program of microcomputer instruction. Yet the library wished to be consistent with its excellent reputation as a "user-friendly" information service, a reputation reenforced by a vigorous program of bibliographic instruction. Therefore, at the time we installed microcomputers we were not prepared to ignore our service orientation and force users to fend for themselves.

${ }^{2}$ Linda Guyotte Stewart and James Markiewicz, "Teaching Information Retrieval: Lessons from Cornell," Wilson Library Bulletin 60) (March 1986): 32-32, 79 . 